\title{
Basal ganglia circuits: what's now and next?
}

\author{
Jose L. Lanciego* \\ Neurosciences Division, Basal Ganglia Neuromorphology Laboratory, University of Navarra, Pamplona, Spain \\ ${ }^{*}$ Correspondence: jlanciego@unav.es
}

The current model of the basal ganglia was introduced two decades ago and has become the basis for most of our current understanding of basal ganglia function and dysfunction. Extensive research efforts have been carried out in recent years leading to unprecedented levels of understanding of the main operational principles underlying the pathophysiology of the basal ganglia. Although somewhat obsolete, the "classical" basal ganglia model developed in the mid 1980s by the "founding fathers" (Penney and Young, 1986; Crossman, 1987; Albin et al., 1989; DeLong, 1990) still maintains a remarkable appeal. This model was shaped mainly by the preponderance of anatomical and physiological data available at the time. In the past few years, the development of a whole range of new technical breakthroughs has boosted the availability of data with paramount importance at a breath-taking speed, and thus incorporating these recent advances to further enrich the classical model has become an urgent need.

With this idea in mind, we took advantage of Frontier's philosophy (peer-review policy, open access, web resources, and so on) to recruit a panel of leading experts in different fields of basal ganglia research to prepare focused reviews in their own areas of expertise. It gives me great pleasure to point out that they all (with only one exception) agreed immediately to participate. Besides invited reviews, eight unsolicited reviews have also been incorporated in this Special Issue after going through the standard review process. In addition to all contributors, it is also worth acknowledging the superb assistance received from all individuals reviewing the submitted manuscripts. As a part of Frontier's policy, the individuals involved in the review process are listed on the front page of each accepted manuscript. Submitted manuscripts were published immediately after acceptance without waiting for the entire Special Issue to be completed. Accordingly, the first paper to be published, prepared by Barroso-Chinea and Bezard (2010), appeared in midSeptember whereas the last paper was issued by Lanciego and Obeso (2011) in July.

Although it is practically impossible to cover the whole range of new arrivals to the field with just one Special Issue, my feeling is that with all things considered we have managed to prepare a body of literature with an adequate balance between solicited and unsolicited contributions, representing a good reference for those trying to get started with the basal ganglia, particularly $\mathrm{PhD}$ students.

With regards to invited contributions, bearing in mind that we are dealing with basal ganglia circuits, a number of topics have been addressed in-depth. Firstly, Reiner et al. (2010) have written a comprehensive review on corticostriatal projections. Nigrostriatal and nigroextrastriatal projection systems are addressed in the contributions made by González-Hernández et al. (2010) and Rommelfanger and Wichmann (2010), respectively. Moreover, since striatal interneurons have often been neglected in the basal ganglia model, there are two contributions devoted to this topic: a review dealing with cholinergic interneurons (Bonsi et al., 2011) and another review focusing on all different types of GABAergic striatal interneurons (Tepper et al., 2010). It is also worth noting that we wanted to stress the role played by subcortical basal ganglia loops in modulating basal ganglia function. Two contributions deal with this topic: one by Redgrave et al. (2010) with a focus on the superior colliculus and the other highlighting the role of the pedunculopontine nucleus in basal ganglia circuitry (MartinezGonzalez et al., 2011).

The main research area that was neglected in this Special Issue is the thalamostriatal system. Although several of the invited senior authors posses an in-depth knowledge of this system, most of them were already engaged in other topics and I did not wish to overwhelm with additional commitments. For those interested in the thalamostriatal system, I would suggest reading recent reviews prepared by Smith et al. $(2009,2011)$. Moreover, the presence of projections arising from the subthalamic nucleus and reaching the ventral motor thalamus directly (without going through the output nuclei) has been reported by Rico et al. (2010). However, this paper was published too close to this issue to merit preparing a focused review and therefore was not considered as potential content for this Special Issue.

Two contributions emphasize a holistic view of basal ganglia function: one addresses the somatotopic organization of basal ganglia (Nambu, 2011) and the other focuses on functional anatomy and dynamic states of basal ganglia circuits (Garcia-Munoz et al., 2010). Finally, in an attempt to provide some clues on basal ganglia dysfunction in diseased states, we have incorporated two invited contributions. The first paper addresses striatal spine plasticity in parkinsonian conditions (Villalba and Smith, 2010), a hot topic that has recently attracted intensive research efforts by the scientific community. The second paper reviews the current knowledge on basal ganglia circuits underlying the generation and maintenance of levodopa-induced dyskinesia (Barroso-Chinea and Bezard, 2010), a clinical entity with devastating effects in the daily lives of parkinsonian patients.

Finally, unsolicited contributions have also played a crucial role in shaping the final outcome of the Special Issue, all of which were very much welcomed. Two manuscripts deal with subcortical striatal afferents from different sources (Day-Brown et al., 2010; Pan et al., 2010), whereas another extensively reviews the degree of segregation of striatal output pathways (Bertran-Gonzalez et al., 2010). One manuscript represents a comparative neuroanatomical work of the tree shrew striatum (Rice et al., 2011). Last but not least, two manuscripts address different aspects, such as basal ganglia circuits underlying sleep-wake regulation (Vetriveland et al., 2010) and thalamocortical integration of cognitive and emotional processes as seen with high-field fMRI. 
All the aforementioned contributions have been collated here in a single e-book. I hope that this information may be useful for novice researchers approaching this exciting research field, the basal ganglia. Once again, my most sincere congratulations to all the individuals involved in any way during the preparation of this Special Issue. In addition to authors, co-authors, and reviewers, I must acknowledge the superb support received from Frontiers Team members at all times.

\section{REFERENCES}

Albin, R. L., Young, A. B., and Penney, J. B. (1989). The functional anatomy of basal ganglia disorders. Trends Neurosci. 12, 366-375.

Barroso-Chinea, P., and Bezard, E. (2010). Basal ganglia circuits underlying the pathophysiology of levodopa-induced dyskinesia. Front. Neuroanat. 4:131. doi: 10.3389/ fnana.2010.00131

Bertran-Gonzalez, J., Hervé, D., Girault, J.A., and Valjent, E. (2010). What is the degree of segregation between striatonigral and striatopallidal projections? Front. Neuroanat. 4:136. doi: 10.3389/fnana.2010.00136

Bonsi, P., Cuomo, D., Martella, G., Madeo, G., Schirinzi, T., Puglisi, F., Ponterio, G., and Pisani, A. (2011). Centrality of striatal cholinergic transmission in basal ganglia function. Front. Neuroanat. 5:6. doi: 10.3389/fnana.2011.00006

Crossman, A. R. (1987). Primate models of dyskinesia: the experimental approach to the study of basal ganglia-related involuntary movement disorders. Neuroscience $21,1-40$.

Day-Brown, J. D., Wie, H., Chomsung, R. D., Petry, H. M., and Bickford, M. E. (2010). Pulvinar projections to the striatum and amygdale in the tree shrew. Front. Neuroanat. 4:143. doi: $10.3389 /$ fnana.2010.00143

DeLong, M. R. (1990). Primate models of movement disorders of basal ganglia origin. Trends Neurosci. 13, 281-285.

Garcia-Munoz, M., Carrillo-Reid, L., and Arbuthnott, G. W. (2010). Functional anatomy: dynamic states in basal ganglia circuits. Front. Neuroanat. 4:144. doi: 10.3389/ fnana.2010.00144

González-Hernández, T., Cruz-Muros, I., Afonso-Oramas, D., Salas-Hernandez, J., and Castro-Hernandez,J. (2010). Vulnerability of mesostriatal dopaminergic neurons in Parkinson's disease. Front. Neuroanat. 4:140. doi: 10.3389/fnana.2010.00140

Lanciego, J. L., and Obeso, J. A. (2011). Past, present and future of the pathophysiological modelo f the basal ganglia. Front. Neuroanat. 5:39. doi: 10.3389/ fnana.2011.00039

Martinez-Gonzalez, C., Bolam, J. P., and Mena-Segovia, J. (2011). Topographical organization of the pedunculopontine nucleus. Front. Neuroanat. 5:22. doi: 10.3389/ fnana.2011.00022
Nambu, A. (2011). Somatotopic organization of the primate basal ganglia. Front. Neuroanat. 5:26. doi: 10.3389/fnana.2011.00026

Pan, W. X., Mao, T., and Dudman, J. T. (2010). Inputs to the dorsal striatum of the mouse reflect the parallel circuit architecture of the forebrain. Front. Neuroanat. 4:147. doi: 10.3389/fnana.2010.00147

Penney, J. B. Jr., and Young, A. B. (1986). Striatal inhomogeneities and basal ganglia function. Mov. Disord. 1, 3-15.

Redgrave, P., Coizet, V., Comoli, E., McHaffie, J. G., Leriche, M., Vautrelle, N., Hayes, L. M., and Overton, P. (2010). Interactions between the midbrain superior colliculus and the basal ganglia. Front. Neuroanat. 4:132. doi: 10.3389/fnana.2010.00132

Reiner, A. N., Hart, N. M., and Deng, Y. (2010). Corticostriatal projection neurons: dichotomous types and dichotomous functions. Front. Neuroanat. 4:142. doi: 10.3389/fnana.2010.00142

Rice, M. W., Roberts, R. C., Melendez-Ferro, M., and Perez-Costas, E. (2011). Neurochemical characterization of the tree shrew dorsal striatum. Front. Neuroanat. 5:53. doi: 10.3389/fnana.2011.00053

Rico, A. J., Barroso-Chinea, P., Conte-Perales, L., Roda, E., Gómez-Bautista, V., Gendive, M., Obeso, J.A., and Lanciego, J. L. (2010). A direct projection from the subthalamic nucleus to the ventral thalamus in monkeys. Neurobiol. Dis. 39, 381-392.

Rommelfanger, K. S., and Wichmann, T. (2010). Extrastriatal dopaminergic circuits of the basal ganglia. Front. Neuroanat. 4:139. doi: 10.3389/fnana.2010.00139

Smith, Y., Raju, D., Nanda, B., Pare, J. F., Galvan, A., and Wichmann, T. (2009). The thalamostriatal system: anatomical and functional organization in normal and Parkinsonian states. Brain Res. Bull. 78, 60-68.

Smith, Y., Surmeier, D. J., Redgrave, P., and Kimura, M. (2011). Thalamic contributions to basal ganglia-related behavioral switching and reinforcement. J. Neurosci. 31, 16102-16106.

Tepper, J. M., Tecuapetla, F., Kóos, T., and Ibáñez-Sandoval, O. (2010). Heterogeneity and diversity of striatal GABAergic interneurons. Front. Neuroanat. 4:150. doi: 10.3389/ fnana.2010.00150

Vetriveland, R., Qiu, M-H., Chang, C., and Lu, J. (2010). Role of basal ganglia in sleepwake regulation: neural circuitry and clinical significance. Front. Neuroanat. 4:145. doi: 10.3389/fnana.2010.00145

Villalba, R. M., and Smith, Y. (2010). Striatal spine plasticity in Parkinson's disease. Front. Neuroanat. 4:133, doi: 10.3389/fnana.2010.00133

Received: 23 January 2012; accepted: 28 January 2012; published online: 13 February 2012. Citation: Lanciego JL (2012) Basal ganglia circuits: what's now and next? Front. Neuroanat. 6:4. doi: 10.3389/fnana.2012.00004

Copyright $(5) 2012$ Lanciego. This is an open-access article distributed under the terms of the Creative Commons Attribution Non Commercial License, which permits non-commercial use, distribution, and reproduction in other forums, provided the original authors and source are credited. 